\title{
Indivíduo e Mistura de Gêneros: Dissonâncias Culturais e Distinção de $\mathrm{Si}^{*}$
}

Bernard Lahire

$\mathrm{D}$

e Thorstein Veblen (1978 [1899]) a Pierre Bourdieu (1979) passando por Edmond Goblot (1925), uma longa tradição intelectual destacou as funções sociais da arte e da cultura nas sociedades diferenciadas e hierarquizadas, e sobretudo os lucros sociais de distinção ligados à apropriação das formas culturais mais raras e mais legítimas. Os sociólogos da cultura já estão acostumados a pensar "a Cultura" (a "alta" ou a "grande" cultura) em suas relações com as classes sociais ou com as frações de classes e a constatar as desigualdades sociais de acesso à "Cultura". Classes sociais e sua distância maior ou menor em relação à cultura dominante, hierarquias culturais que classificam os grupos, instituições, obras e práticas do mais legítimo ao menos legítimo, eis os elementos-chave da interpretação sociológica das práticas e preferências culturais há 40 anos na França (Bourdieu, 1979; Bourdieu et alii, 1965; Bourdieu e Darbel, 1969), como nos Estados Unidos (Lynes, 1954; Murphy, 1988; Levine, 1988; Beisel, 1990). A situação social global descrita desde meados dos anos 1960 na França pode ser resumida da seguinte forma: classes dominantes "cultas", com uma relação fácil com a cultura para aqueles que tiveram uma educação cultural precoce; classes médias caracterizadas por "boa vontade cultural" e tensão hi-

*[A tradução do original em francês “Individu et Mélanges des Genres: Dissonances Culturelles et Distinction de Soi" é de Estela Abreu.]

DADOS - Revista de Ciências Sociais, Rio de Janeiro, Vol. 50, n-4, 2007, pp. 795 a 825. 
percorretiva, oscilante entre o "nobre" e o "popular"; e classes dominadas mantidas à distância da Cultura e sob permanente vergonha ou indignidade cultural.

Esse é o esquema que pode ser questionado adotando-se uma perspectiva de conhecimento diferente daquela que analisa apenas as distâncias interclasses: perspectiva que considere de modo sistemático as práticas e as preferências culturais sob o ângulo da variação intra-individual dos comportamentos (Lahire, 2004).

Ao proceder assim, lança-se outro olhar sobre a tão debatida e complexa questão dos públicos da cultura. A história cultural francesa foi levada, há já quase 20 anos, a discutir o uso pouco reflexivo e muito automático de categorias de classificação dos "públicos" ou "populações" mantidas por muito tempo como evidentes na história estatística. Por exemplo, em vez de utilizar categorias sociais que não foram pesquisadas (elite/povo, dominantes/dominados, hierarquias socioprofissionais ou socioculturais) para conseguir detectar as diferenças culturais, o historiador Roger Chartier propõe o caminho inverso: partir dos objetos, das obras, dos códigos, das formas, dos dispositivos simbólicos, a fim de reconstruir as comunidades que deles se apropriam. Descobrem-se então princípios - plenamente sociais - de diferenciação relativamente inéditos, que uma "visão mutilada do social" (1989:1.511) tinha feito esquecer: sexo, geração, situação familiar (celibato, viuvez, casamento etc.), confissão religiosa, tradição educativa e corporativa, escolaridade, posição intelectual etc. Mas em vez de ir dos objetos, instituições ou práticas para os públicos que os atraem e que deles se apropriam, também é possível indagar como os mesmos indivíduos podem fazer parte de públicos tão diversos (público da televisão, do rádio, do teatro, do cinema, dos museus, das salas de concerto, da literatura etc., mas também públicos de certos gêneros de programa, de espetáculo, de filme, de música, de literatura etc.), por vezes nitidamente heterogêneos. Quem se concentrar demais na lógica das interpretive communities (comunidades interpretativas), no sentido de Stanley Fish (1980), pode acabar esquecendo que os indivíduos costumam passar de uma "comunidade" para outra e que se caracterizam, sob esse aspecto, por uma pluralidade de pertencimentos sociais e simbólicos, inserindo suas práticas (e sobretudo suas práticas culturais) em múltiplos lugares e tempos. 


\section{O QUE REVELA A MUDANÇA DE PERSPECTIVA DE CONHECIMENTO?}

Não se trata absolutamente de negar a existência de desigualdades sociais diante das formas culturais mais legítimas, e sobretudo o papel sempre central do capital cultural no acesso às formas mais eruditas de cultura. Mas a mudança de escala de observaç̧ão permite esboçar outra imagem do mundo social. Começando por considerar as diferenças internas à série de comportamentos e de gostos de cada indivíduo (variações intra-individuais: o mesmo indivíduo faz isto $e$ aquilo, gosta disto mas gosta também daquilo, gosta disto mas em compensação detesta aquilo etc.) antes de voltar às diferenças entre classes sociais (variações interclasses), chega-se a uma representação do mundo social que não descarta as singularidades individuais e evita a caricatura cultural dos grupos sociais. Vê-se então que a fronteira entre a legitimidade cultural (a "alta cultura") e a ilegitimidade cultural (a "subcultura", o simples "divertimento") não separa apenas globalmente (estatisticamente) as diferentes classes, mas divide as diferentes práticas e preferências culturais dos mesmos indivíduos, em todas as classes da sociedade. Sejam quais forem suas características sociais (classe social, nível de diploma, idade ou sexo), a mesma pessoa terá muitas probabilidades estatísticas de ter práticas e gostos variáveis sob o ângulo da legitimidade cultural, segundo as áreas (cinema, música, literatura, televisão etc.) ou as circunstâncias da prática.

Em escala individual, dois grandes fatos impõem-se à análise. O primeiro é a forte freqüência estatística dos perfis culturais individuais compostos de elementos heterogêneos, dissonantes (no sentido em que alguns pertencem a registros culturais muito legítimos e outros a registros culturais quase nada legítimos): esses tipos de perfis são absoluta ou relativamente majoritários em todos os grandes grupos sociais (embora mais prováveis nas classes médias e superiores que nas classes populares), em todos os níveis de diploma (mesmo que bem mais prováveis entre os que concluíram no mínimo o curso secundário) e em todas as faixas etárias (embora cada vez menos prováveis à medida que a idade aumenta). O segundo fato a destacar é a maior probabilidade, para os indivíduos que compõem a população pesquisada, de ter um perfil cultural consonante "por baixo" (de fraca legitimidade) que "pelo alto" (de forte legitimidade): seguindo assim a pirâmide das condições sociais, é sociologicamente bem mais difícil manter um alto nível de legitimidade cultural em uma série de domínios do que se manter afastado de toda forma de legitimidade cultural ${ }^{1}$. 
Se retivermos os resultados conseguidos na escala das variações intergrupos e na escala das variações intra-individuais, é possível dizer que os indivíduos das sociedades contemporâneas têm, ao mesmo tempo, uma forte probabilidade de se comportar como os outros membros do grupo social a que pertencem $e$ uma forte probabilidade de não ter apenas comportamentos ligados ao grupo social a que pertencem, ou seja, forte probabilidade de ter alguns comportamentos atípicos em relação ao grupo social a que pertencem. Por isso, cabe afirmar que não há nada mais estatisticamente freqüente que a singularidade individual e, por conseguinte, que as exceções estatísticas nada têm de excepcional: é o que há de mais comum, e tais exceções tocam a maioria dos indivíduos que compõem os diferentes grupos sociais.

Ao contrário do que se imagina, a questão dos comportamentos estatisticamente "marginais" (ou atípicos) está longe de ser marginal do ponto de vista sociológico, isto é, ela não constitui um interesse de segunda ordem para o sociólogo que não tenha como único objetivo comentar as tendências estatísticas mais acentuadas. Esse lugar primordial das "margens" aparece com clareza quando, em vez de considerar os vínculos entre grupos (ou categorias) e práticas ou preferências, focalizam-se os indivíduos que compõem os grupos e observam-se suas práticas e preferências em diferentes compartimentos ou subcompartimentos de sua vida cultural. Adotando aqui (por exemplo, em matéria de gostos cinematográficos e preferências literárias) o comportamento típico ou modal de seu grupo (aquele que é o mais freqüentemente ligado ao grupo social a que pertence), ele é lá (por exemplo, em matéria de gostos musicais ou de consumo televisual) marginal no sentido de seu comportamento não ser estatisticamente o mais freqüente no grupo social ao qual pertence. Típicos e marginais ao mesmo tempo, é o que quase sempre são considerados os indivíduos na longa seqüência de seus comportamentos. Em um ou em outro grau, em tal ou qual setor de seus comportamentos, qualquer indivíduo, aliás o mais conforme à cultura de seu grupo, ficará entre as exceções estatísticas e comportar-se-á como a maioria dos membros de outro grupo. Se desdenharmos as margens ou as exceções estatísticas, não estaremos perdendo apenas as beiras do quadro, mas o quadro inteiro.

\section{PLURALIDADE DAS ORDENS DE LEGITIMIDADE CULTURAL E PERFIS INDIVIDUAIS}

Ao contrário do que as derivas legitimistas da teoria da legitimidade cultural conseguiram fazer crer (Grignon e Passeron, 1989), saindo da 
zona institucionalmente balizada e controlada pela Escola, a legitimidade cultural nem sempre dispõe de meios para impor-se como uma evidência. Numerosos casos de "resistência" (fraca ou forte, circunstancial ou permanente) à ordem cultural dominante são observáveis, e constata-se que a pluralidade dos grupos ou instituições (dos maiores aos mais restritos; dos mais duradouros aos mais efêmeros) que compõem a formação social produz ordens de legitimidade específicas mais ou menos fortes e mais ou menos duráveis. A possibilidade de resistir à legitimidade cultural dominante (ainda hoje, apesar de profundas mudanças em curso, de ordem principalmente literária e artística) sempre se baseia em grupos ou instituições possuidores de lógicas concorrentes: grupos de pares, meio familiar, meio profissional, comunidade religiosa, fã-clube, rede de sociabilidade, instituição midiática etc.

Por motivos tanto teóricos (a crítica na ordem teórica de deslizes legitimistas da teoria da legitimidade cultural) quanto históricos (as transformações históricas da oferta cultural durante os últimos 40 anos), é impossível continuar como se estivéssemos diante de um espaço cultural homogêneo sob o ângulo da legitimidade, isto é, estruturado de parte em parte pela unívoca oposição legítimo/ilegítimo; oposição que todos conheceriam e executariam, à qual todos concederiam o mesmo significado e na qual todos acreditariam com a mesma intensidade. Não se pode fazer de conta que existe uma identidade de crenças culturais no mesmo momento em todas as regiões do mundo social, como se o conjunto dos grupos sociais tendesse a alinhar-se pelos consumos legítimos dos membros mais "cultos" das frações intelectuais da classe dominante.

Ora, mudando o enfoque e olhando o mundo social pela escala dos indivíduos, percebe-se que cada indivíduo é suscetível de participar sucessiva ou simultaneamente de vários grupos ou instituições, e tenta-se encontrar os meios para compreender sociologicamente os motivos das maiores ou menores variações intra-individuais dos comportamentos culturais. A variação intra-individual das práticas e preferências culturais é o sinal e o sintoma, na escala do social incorporado, por um lado, da pluralidade da oferta cultural e, por outro, da pluralidade dos grupos sociais (dos mais micro aos mais macro), capazes de sustentar (suportar) essas diferentes ofertas culturais e de difundir hierarquias culturais específicas que compõem nossas formações sociais tão diferenciadas. Ela é o produto da forte diferenciação social, e mais precisamente da pluralidade das influências socializadoras, dos con- 
textos e dos tempos da prática. Por conseguinte, a compreensão das realidades mais individuais não remete à singularidade irredutível dos destinos individuais, nem à "liberdade de escolha" de indivíduos "autônomos" (e desimpedidos de todos os determinantes sociais), mas, ao contrário, remete à estrutura de conjunto das sociedades que as produziram.

A pluralidade dos grupos (ou instituições) e a multiplicidade dos quadros de vida social que cada indivíduo pode freqüentar simultaneamente (de fato, alternativamente) ou sucessivamente (no decorrer da vida) estão ligadas à forte diferenciação social das funções características de nossas sociedades. A realidade social é portanto mais complexa do que o que a teoria da legitimidade cultural dá a entender. E o estudo sistemático das variações intra-individuais dos comportamentos culturais - que obriga a que se vejam os deslocamentos efetuados por um mesmo indivíduo de um registro cultural para outro - enfatiza a pluralidade dos "subsistemas" (Passeron, 1991:109) com os quais os atores têm de conviver.

\section{REVOGAÇÃO DE UM MODELO: O CONSUMIDOR DEFINIDO POR SEUS "GOSTOS" CULTURAIS}

O estudo preciso e circunstanciado das variações intra-individuais das práticas culturais questiona radicalmente o modelo implícito de um "consumidor cultural" definido essencialmente por seus gostos pessoais. Quanto mais se examinam com cuidado as práticas culturais, mais dúvidas aparecem em matéria de percepção dos "gostos", que são quase sempre considerados um marcador fundamental da identidade social dos indivíduos. De fato, quando a análise baseada em entrevistas consegue mostrar que muitas práticas culturais individuais, e por vezes a grande maioria delas, não estão ligadas a gostos mas a circunstâncias instigadoras, obrigações ou injunções leves ou fortes de todo tipo, cabe indagar se os indivíduos em questão se definem mais pelo que consideram próprio da sua esfera de gostos pessoais ou pela multidão de suas práticas efetivas. Os gostos aparecem então como a parte visível - e destacada - de um enorme iceberg.

O modelo de um consumo cultural fundado no gosto individual baseia-se na imagem simplificada de indivíduos reduzidos a meros representantes oficiosos (enquanto dura a enquete sociológica) de classes, de frações de classe ou de grupos sociais; indivíduos caracterizá- 
veis por gostos pessoais que são essencialmente os gostos de sua classe. Ora, é preciso ressituar esses indivíduos muito abstratos na rede concreta de suas ligações de interdependência a fim de obter uma imagem um pouco mais justa do que são os consumos e as atividades culturais.

As variações intra-individuais das práticas culturais sob o aspecto do seu grau de legitimidade levam a reintroduzir outros "motivos" na explicação das práticas culturais, além do gosto e da paixão pessoais: a prática por obrigação escolar, por imposição profissional ou por imposição de uma situação excepcional, a prática habitual sem gosto particular, o acompanhamento mais ou menos desejado de outrem (filhos, cônjuge, amigos), a prática por cortesia (para agradar ou não aborrecer pessoas de que se gosta), o desejo pessoal de descansar ou de espairecer pelo consumo de bens culturais ou pela prática de atividades culturais que não estão no topo da hierarquia de suas preferências, a estrita delimitação temporal (tempo de férias, de uma festa etc.) de uma folga que a pessoa se concede, a "simples" curiosidade ou a boa vontade sem entusiasmo, o consumo irônico (de "segundo grau") ou, ainda, o consumo em contexto de gratuidade do acesso à oferta que compromete menos pessoalmente, enfim, todas as modalidades menos intensas (às vezes mínimas) e menos francamente positivas e entusiásticas (às vezes até ambivalentes) do consumo cultural ${ }^{2}$.

\section{CONDIÇÕES DE PRODUÇÃO DE PERFIS CULTURAIS HETEROGÊNEOS}

O estabelecimento de uma série de novos fatos estatísticos relativos aos perfis culturais individuais dissonantes (os mais freqüentes) e consonantes (os mais raros) leva a esclarecer as condições sociais e históricas de produção dessas variações intra-individuais dos comportamentos culturais. A análise pormenorizada dos retratos culturais individuais permite mostrar que todas essas variações podem ser reduzidas ao problema central da exposição do indivíduo a influências socializadoras heterogêneas: efeito de uma trajetória de mobilidade social ou profissional ascendente ou declinante, efeito de uma rede de relações culturalmente diversificada, efeito de uma relativa heterogamia do casal sob o aspecto cultural, efeito da interiorização de preferências escolares defasadas com referência às do meio de origem, efeito das injunções conjugadas que vive a juventude escolarizada (entre grupo de pares, escola e família) $)^{3}$, efeito de influências socializadoras contraditórias provindas de instâncias culturais concorrentes (família, escola, tevê, imprensa 
etc.), efeito de influências culturais dentro da própria família de origem etc. ${ }^{4}$

E, para compreender a importância adquirida por essas influências socializadoras heterogêneas em matéria cultural, convém explorar diferentes dimensões de nossas formações sociais: as mobilidades sociais, escolares ou profissionais, as imposições e influências relacionais, a diminuição de intensidade da crença na cultura literária e artística, a necessidade de um "relaxamento" (público ou privado) das tensões em uma sociedade em que os compromissos profissionais e escolares são intensos, os efeitos do acesso cada vez mais privado aos bens culturais (televisão, rádio, vídeos etc.) e a natureza da oferta que incita à mistura de gêneros outrora separados.

\section{Pequenas e Grandes Mobilidades Individuais}

Parte dos perfis culturais dissonantes explica-se por situações de mobilidade social (o indivíduo não tem a mesma posição social dos pais), escolar (o indivíduo não tem o mesmo nível escolar dos pais ou aumentou seu próprio capital escolar por ter retomado os estudos) ou profissional (o indivíduo mudou de posição na hierarquia profissional). Se tais mobilidades, pequenas ou grandes, muitas vezes se traduzem por uma heterogeneidade das práticas e preferências culturais do ponto de vista de seu grau de legitimidade, é porque os indivíduos que tiveram essa experiência ocuparam posições diferentes nas hierarquias social, cultural ou profissional e, por isso, freqüentaram ambientes socializadores ou agentes socializadores variados. Conviveram ou confrontaram-se com registros culturais diferentes dos que conheciam anteriormente e, por esse motivo, conservam em si, sob a forma de disposições mais ou menos fortes, os vestígios do conjunto dessas experiências socializadoras heterogêneas, por vezes até nitidamente contraditórias.

A esses deslocamentos individuais, podem acrescentar-se as distâncias culturais possíveis entre cônjuges, pois os casais não são perfeitamente homógamos (raramente têm as mesmas posições sociais e as mesmas origens sociais, os mesmos níveis de escolaridade e diplomas de mesma natureza etc.) e, por conseguinte, não contraíram necessariamente os mesmos hábitos e as mesmas preferências culturais. É possível também evocar as distâncias culturais entre os membros de uma mesma rede de sociabilidade entre amigos; ou ainda as múltiplas mudanças significativas de contexto relacional e cultural (mudança de do- 
micílio seguida de recomposição da rede de sociabilidade, mudança de contexto profissional, novo casamento etc. $)^{5}$.

Considerando o conjunto desses dados sob o aspecto dos efeitos que produzem nas socializações infantis, cabe dizer que um dos grandes resultados é que as crianças são levadas a viver situações sociais (familiares principalmente) nas quais o confronto de normas sociais, de modos de ver, de sentir e de agir, de gostos ou de preferências relativamente heterogêneas e, por vezes, contraditórias, são historicamente cada vez mais freqüentes e precoces (Lahire, 1998).

\section{A Crise de Fé na Cultura Literária e Artística}

Queda importante da proporção dos fortes leitores entre os detentores de diplomas superiores e entre os profissionais superiores, independentemente da origem social, menor freqüência nos teatros e salas de concertos (Dumontier, Singly e Thélot, 1990): os dados de enquetes podem não afiançar os discursos catastróficos deplorando o declínio cultural ou a "derrota do pensamento", mas assinalam transformações significativas na relação dos franceses (inclusive das elites) com a cultura desde os anos 1960.

A cultura legítima clássica foi de certa forma vítima durante os últimos 40 anos da ascensão da cultura científica (dentro do sistema escolar) e da extensão da cultura de lazer (promovida pela indústria mais rentável dos lazeres e da cultura). As novas relações de força entre cultura literária e cultura científica, por um lado, e cultura literária e artística e culturas do divertimento, por outro, explicam a queda significativa de intensidade da fé na cultura literária e artística. E tal enfraquecimento contribuiu para tornar mais prováveis as saídas de registros culturais para todos que, até então, tinham como ponto de honra evitar as regiões mais comerciais, ligadas ao divertimento e populares ou estigmatizadas como infraculturais, embrutecedoras ou vulgares.

\section{Descanso e Liberação}

Se os indivíduos de perfis culturais legítimos muito consonantes são bem raros é porque, até os mais dotados do ponto de vista escolar, são obrigados pela vida social (profissional sobretudo) a moderar suas exigências culturais e a adotar uma política mais flexível de alternância entre momentos especificamente culturais (e que eles percebem como tais: momentos de "instrução", de "enriquecimento" ou de "eleva- 
ção") e momentos de divertimento. Donos de grandes capitais culturais que dispõem de pouco tempo fora do trabalho, vidas profissionais ou escolares extenuantes e cansativas, duplas vidas profissionais e familiares (particularmente pesadas para as mulheres), tudo isso ajuda a explicar a produção social de uma "necessidade" de participação sem complicação em coisas comuns, informais, divertidas, em emoções coletivas, em momentos festivos, enfim, em culturas "quentes"6 sem nenhum "conteúdo cultural" propriamente dito, se "cultural" for entendido como essa mais-valia específica que o conhecimento ou a reflexão podem trazer a toda situação vivida. É bem diferente da figura do Homem culto que aproveita o tempo fora do trabalho para se ilustrar e aprender. Doravante, os mais diplomados podem, como os outros, procurar o relaxamento que diverte após a extenuante jornada de trabalho.

Os entrevistados costumam opor - sejam quais forem suas condições sociais - trabalho (escolar ou profissional), obrigações, esforço, cansaço, tensões, complicações, dificuldades, contrariedades, brigas, preocupações ou estresse, de um lado, a descanso, relaxamento, descontração, descompressão, facilidade e expansão, de outro. Assistir à televisão ou ao cinema, ir a espetáculos ou ler "coisas fáceis" (mesmo que se saiba que são "fraquíssimas", "débeis", "idiotas", "estúpidas" ou "bobocas"), que não exigem "esforço", tudo isso permite "não pensar em nada", "não quebrar a cabeça", "lavar a cuca"7, "fazer lobotomia", "liberar ou descansar a mente", "esvaziar a cabeça", "entregar-se", "distrair-se", "descansar", "divertir-se", "soltar-se", "espantar os problemas", "deixar de lado as preocupações" e até "dormir".

Nobert Elias aventou a hipótese de que as atividades de lazer têm a função social de "contrabalançar as tensões e o estresse desagradável das sociedades, e trazer uma forma de descanso". São "antídoto contra as tensões" (Elias e Dunning, 1944:56). Nesse sentido, é possível afirmar que, quanto mais as sociedades ou os grupos sociais dentro das formações sociais exigem alto grau de tensão e de estresse da parte de seus membros, tanto mais certos lazeres tornam-se necessários para relaxar, na vida pública ou privada, as tensões. Tais relaxamentos das obrigações podem repetir-se, mas só ocorrer em tempos estritamente delimitados. Por essa razão, a mais séria cultura erudita pode perfeitamente coexistir nos mesmos indivíduos com a cultura do relaxamento ou do entretenimento ${ }^{8}$. 


\section{Consumos gratuitos e privados: o enfraquecimento dos efeitos de legitimidade}

A televisão e o rádio trouxeram a cultura "para grande público" que coincide em parte com os gostos populares hedonistas de divertimento e de informalidade (Verret, 1988). Ao defender publicamente, cotidianamente e junto a um grande público a primazia da distração ou do repouso sobre a cultura literária e artística ou científica, ela muito contribuiu para a queda geral do grau de crença na cultura legítima dominante, para a desculpabilização dos consumidores quanto aos "erros culturais" cometidos bem como para o reforço de todas as formas populares ou dominantes de antiintelectualismo (dos operários aos patrões, passando por todos os dirigentes de formação científica e técnica). Essa mídia só podia ajudar a diminuir a força dos efeitos de legitimidade e a derrubar o grau de vergonha cultural sentida pelas populações mais afastadas dos legítimos detentores da cultura como por aquelas que lhes são a priori as mais próximas ${ }^{9}$.

Mas uma das maiores transformações da ordem cultural das coisas, cuja importância pouco foi lembrada até agora, refere-se às condições privadas de "consumo" desses novos produtos culturais, que não deixam de ter efeito sobre a relação que os consumidores mantêm diante das normas culturais legítimas dominantes. De fato, televisão, rádio, alta-fidelidade, vídeo, leitor de DVD e, mais recentemente, computador e internet, introduziram muitos produtos culturais na esfera privada. Ora, o que acontece com as normas culturais quando se entra na intimidade dos lares e elas se refletem no espaço doméstico "privado"? Resistem às situações entre si, ou até de consumo solitário, nas quais já não se teme o olhar "desaprovador" e o juízo cultural (negativo) externo?

De fato, constata-se que a esfera privada é propícia ao relaxamento de controle das emoções, à expressão das disposições menos formalistas e mais hedonistas (menor controle do olhar alheio, menor tom oficial e menor formalidade da situação) e, por isso mesmo, propícia aos consumos culturais de maior diversão ${ }^{10}$. Em vez de superavaliar a intensidade da fé em matéria de cultura legítima entre os mais dotados culturalmente, a percepção dos diferenciadores culturais individuais permite observar a variedade dos momentos em que gostos e tendências muito diversos se exprimem. Por exemplo, ao pensar espontaneamente que o grande leitor de romances ou de ensaios legítimos vai desdenhar com 
certeza - senso de dignidade cultural exige - a televisão (assistindo pouco) ou vai ter um consumo muitíssimo seletivo (só assistindo ao que há de mais cultural nos programas existentes), a teoria da legitimidade cultural apóia-se implicitamente em uma teoria do ator que pressupõe sua monocoerência, sua homogeneidade disposicional e esquece a variação dos contextos. Ora, a enquete empírica destrói tais evidências eruditas fazendo surgir a possível (e até freqüente) variação das disposições, atitudes, gostos ou interesses culturais em função sobretudo da área de prática considerada, de seu status e das circunstâncias da prática.

Os dispositivos televisual e radiofônico colocados na intimidade doméstica - tornando o consumo dos espetáculos de tevê (filmes, telefilmes, minisséries, programas humorísticos e jogos etc.) ou dos produtos radiofônicos (música, jogos e divertimentos etc.) um consumo privado (individual, o casal ou a família) - fizeram historicamente cair de modo considerável o grau de vergonha cultural sentida, e abriram para públicos em princípio mais recalcitrantes (por sua alta formação escolar) as vias do consumo de produtos comerciais "para grande público".

A segunda grande característica do consumo televisual e radiofônico, que acompanha a privatização, mas que traz sua contribuição específica à facilitação dos consumos heterogêneos em relação ao registro cultural mais esperado, é a gratuidade do consumo. A simples "liberdade" de olhar programas na tevê ou escutar programas de rádio "por curiosidade", porque se sabe que é possível desligar à vontade, sem ter gastado nada, modifica fundamentalmente a relação com a oferta cultural se comparada com a situação do público de filmes em salas de cinema, que exige gastos consideráveis e supõe escolhas. Porque o ato de pagar não tem apenas significado econômico: pagar voluntariamente para chegar a um bem cultural é comprometer algo de si. Pagar (dar dinheiro) para aceder a um bem determinado é também, de certo modo, "fazer um esforço", mostrar suas prioridades, preferências, escolhas. E percebe-se, ao inverso, que a evocação da gratuidade pode mostrar distância para com o objeto consumido (vários entrevistados fazem o seguinte raciocínio: "Quando é gratuito, não presto muita atenção. Mas, se for preciso pagar, sou mais exigente, seleciono, escolho").

O rádio e a televisão são assim fornecedores permanentes, ao mesmo tempo privados e gratuitos, de imagens e/ou de sons que permitem 
uma ligação mais ampla e mais flexível com os produtos culturais do que o acesso pago nos espetáculos e obras culturais (cinema, teatro, música, dança, ópera etc.) ou o acesso gratuito a certas obras culturais mas que exigem um deslocamento e, em certos casos, um consumo público (museus, exposições, bibliotecas etc.). O rádio e a televisão tornam possível o acesso imediato a produtos culturais que nunca se teria a idéia de pagar para consumir. E esse modo de pensar vale tanto para os públicos de fraco capital escolar que hesitam em pagar para ver um espetáculo (filme, peça de teatro etc.) que poderiam não entender ou que poderia ser aborrecido, quanto para os públicos de forte capital escolar que, quando têm de escolher, são levados mais por lógicas de busca da "qualidade" e da "dignidade" culturais ${ }^{11}$.

\section{Os símbolos televisuais de uma época de mistura de gêneros}

A "mistura" de gêneros não é visível apenas na paleta das práticas e das preferências culturais dos "consumidores". Aparece também na própria natureza de uma parte da produção cultural. A não ser que seja esta que se adapte a partir de então aos diferenciadores culturais individuais, interpretando-a como um ecletismo dos gostos característicos dos indivíduos que compõem sua audiência. Se, por vezes, foi feita uma ligação entre ecletismo da oferta e diversidade dos públicos (o ecletismo audiovisual tentando, em uma estratégia de "agradar a todos", atingir públicos diferentes em um único e mesmo programa com convidados e assuntos dos mais diversos), nunca foi feita uma prospecção sistemática da hipótese de uma diversidade cultural própria a cada indivíduo. Quando se invoca o ecletismo dos públicos mais diversos, pressupõe-se o caráter homogêneo dos gostos desses diferentes públicos, mas descarta-se a questão da possível mistura cultural das preferências em cada indivíduo que os compõem.

Tudo se passa como se a nova estrutura da oferta, caracterizada pela mistura de gêneros, dos mais nobres aos mais comuns, fosse ao mesmo tempo reflexo de novas estruturas de percepção e de apreciação (que costumam gostar de misturas e até as procuram) e o que contribui para formá-las, isto é, forjar os hábitos mentais e o gosto pelo variado, pelo diverso, pela mistura (até então) improvável de gêneros etc. A mistura ou indiferenciação de gêneros é portanto mais que uma estratégia. É potencialmente uma verdadeira fórmula geradora das práticas e das representações, isto é, uma disposição ou um hábito cultural que questiona as separações, as delimitações, as fronteiras que costumavam ser delinea- 
das com firmeza. E quem continua a perceber e apreciar as coisas do ponto de vista da "necessária" distinção dos gêneros só pode ver nessas misturas confusões (de gêneros e de valores), uniões antinaturais ou degradantes, portadoras de relativismo cultural (e isso, apesar de essa mistura poder respeitar as diferenças de legitimidade entre os elementos que a compõem). Como afirmava Pierre Bourdieu: "O mais intolerável, para os que se julgam detentores do gosto legítimo, é sobretudo a reunião sacrílega dos gostos que o gosto manda separar" $(1979: 60)^{12}$.

Na França, o símbolo televisual de uma época marcada pela mistura de gêneros culturais é o programa Tout le Monde en Parle [Todo o mundo fala disso] produzido e animado por Thierry Ardisson (France 2). "Ele mistura todos os gêneros para grande prazer dos telespectadores", lê-se em um site da internet (Actustar) que dedica algumas páginas a este último. $\mathrm{O}$ "grande prazer dos espectadores" é decerto uma suposição dos autores do texto, e seria possível evocar igualmente a irritação de outros telespectadores diante desse tipo de espetáculo. "O que é lamentável em Thierry Ardisson", escreve o jornalista Hugo Cassavetti, "é sua mania de misturar tudo, a política e o sexo, o sério e o trivial, a pertinência e a insolência, no meio de um show heteróclito e barulhento no qual desfilam modelos bem avantajadas e um DJ difícil de atrair multidões" (Cassavetti, 2002).

Em compensação, cabe dizer que é essa "mistura de gêneros" a estratégia consciente que preside tanto a composição das atrações ${ }^{13}$ como as variações de tipos de perguntas durante uma entrevista. Utilizando a mistura explosiva dos temas (política, esporte, música, literatura, filosofia, cinema, teatro) e das legitimidades (do presidente da Assembléia Nacional a uma atriz pornô, de um prêmio Goncourt a um cômico popular considerado "vulgar" pela imprensa cultural legítima), Ardisson é muitas vezes apresentado como "o único que se esfalfa na tevê para juntar o cultural com o popular" (idem).

A mistura, que não é praticada só por ele (o que se depreende do estudo de programas de tevê tais como On ne Peut pas Plaire à Tout le Monde [Não se pode agradar a todo o mundo], Campus, ou, em uma época ligeiramente anterior, Nulle Part Ailleurs [Em nenhum outro lugar] ${ }^{14}$ ), era muito mais improvável em um estágio anterior da oferta televisual (com programas literários como Lectures pour Tous [Leituras para todos] de Pierre Desgraupes e Pierre Dumayet ou mesmo Apostrophes [Apóstrofos] de Bernard Pivot), em que o respeito das fronteiras cultu- 
rais era muito maior do que é hoje. De fato, quando os políticos, escritores, atores, desportistas, cômicos etc. tinham programas específicos, era raro vê-los lado a lado em um mesmo estúdio de televisão. Não estamos muito longe dos dispositivos espetaculares descritos pelo historiador norte-americano Laurence $\mathrm{W}$. Levine: durante a primeira metade do século XIX na América do Norte, misturavam-se indiscriminadamente cenas das peças de Shakespeare, trechos de comédias, cantores populares, mágicos ou malabaristas com trechos de ópera (Levine, 1988).

\section{O GOSTO DOS OUTROS E AS DISTINÇÕES DE SI}

Ao considerar os fenômenos de variações intra-individuais das práticas e preferências culturais, não se questiona a existência de desigualdades sociais diante da cultura, nem a função social das formas culturais legítimas dominantes em uma sociedade hierarquizada. Mas destaca-se um tipo particular de função social ligada aos processos de diferenciações individuais e de construção social dos indivíduos em sociedades diferenciadas.

A principal conseqüência da muito freqüente mistura dos perfis culturais individuais é que, ao contrário do que aparentam muitos discursos públicos, os indivíduos não vivem a distinção entre legítimo e ilegítimo apenas como fronteira que separa grupos ou classes diferentes ("eles" e "nós"), mas como linha de demarcação que diferencia os diversos membros de um mesmo grupo (os juízos de "vulgaridade" ou de "fraqueza" cultural são muitas vezes emitidos sobre as pessoas socialmente mais próximas: membros da família restrita ou ampliada, grupos de pares, colegas de trabalho, cônjuge etc.) e como linha divisória entre si e si (os mesmos juízos culturais estigmatizantes podem dirigir-se a uma parte de suas práticas pessoais passadas ou presentes), linha discriminatória que os atravessa intimamente. O que, do ponto de vista estatístico, separa os grupos ou as classes da sociedade, atravessa também em um ou em outro grau (a constatação é também estatisticamente fundamentada) grande parte dos indivíduos que compõem o conjunto de grupos ou classes. A separação entre legítimo e ilegítimo pode ser assim vivida como uma divisão interna, que pode provocar em certos casos lutas de si contra si (Lahire, 2005). E essa internalização ou interiorização da oposição, da luta ou do combate, permite, afinal, que cada um domine mais ou menos as categorias "nobre" e "vulgar", "alto" e "baixo", "grande" e "pequeno", "digno" e"indigno", "puro" e 
"impuro", "refinado" e "grosseiro", "raro" e "comum", "inteligente" e "burro" etc., como categorias de percepção dos comportamentos e dos bens culturais.

Vivemos em sociedades diferenciadas e hierarquizadas, com mobilidade social e geográfica muito mais forte que numerosas sociedades tradicionais; sociedades altamente escolarizadas, mas marcadas também por fortes concorrências educativas e culturais pela "pesca das almas" (segundo a bela expressão de Max Weber). As condições de existência e de coexistência nesse tipo de formações sociais são tais que é estatisticamente raro para determinado indivíduo ficar restrito apenas ao registro da alta legitimidade cultural ou ao da ilegitimidade cultural.

Como meio de legitimação (coletivo ou individual), as formas dominantes de cultura fornecem um quadro que permite aos indivíduos dar um sentido distintivo a suas práticas e seus gostos e sentir-se justificados por existir como existem, ter o sentimento de levar uma vida digna de ser vivida, isto é, levar uma vida mais digna de ser vivida do que outras (Lahire, 1999). Função moral de apoio e de garantia da cultura como cultura legítima. Mas se o mundo social é um campo de batalha, também muitas vezes os indivíduos que o compõem são eles próprios a arena de uma luta de classificações. E a luta de si contra si, a predominância de um si legítimo sobre a parte ilegítima de si, o controle e o domínio do que há de ilegítimo em si contribuem para reforçar o sentimento de superioridade distintiva em relação àqueles que se imagina não terem nenhum domínio nem controle de si (sujeitos à sua pulsão ${ }^{15}$ etc.). Domínio de si e domínio de outrem estão portanto indissociáveis; as distinções e as lutas simbólicas são tanto individuais (intra-individuais e interindividuais) quanto coletivas (interclasses).

\section{DO MODELO DE CONSUMO CULTURAL ONÍVORO AO ESTUDO DA VARIAÇÃO INTRA-INDIVIDUAL DOS COMPORTAMENTOS}

A partir de um quadro conceptual próximo da teoria do capital cultural e do espaço social dos estilos de vida de Pierre Bourdieu, Richard A. Peterson formulou novas hipóteses com base em resultados de grandes enquetes quantitativas a respeito das preferências musicais nos Estados Unidos. Embora ele defenda e valide em parte a hipótese de que os gostos musicais são marcadores de estilos de vida e que estão presentes de modo desigual nas diferentes classes sociais, chega no entanto às seguintes conclusões relativas ao gosto das elites: 
“[...] o gosto das elites já não é definido como a apreciação expressa das formas artísticas mais cultas (e como um desdém moral ou uma tolerância meio perplexa em relação a todas as outras expressões estéticas). Atualmente está sendo redefinido como a apreciação da estética de cada forma distinta, juntamente com a apreciação das artes eruditas. Como o status provém do conhecimento e participação (quer dizer, do consumo) em todas as formas, o termo onívoro parece apropriado" (Peterson e Simkus, 1992:169, ênfase no original).

Os trabalhos de Peterson que se referem essencialmente às preferências musicais mostram que não só são frações minoritárias das classes superiores que consomem os gêneros mais legítimos (o que é confirmado por minhas pesquisas) mas também que as classes superiores não limitam seus gostos ao domínio legítimo.

De minha parte, tentei elaborar um modelo teórico de explicação das práticas e preferências culturais que coincide com o ponto de vista de Peterson e com muitos de seus resultados, mas que vai mais além. Faço algumas reservas ou críticas parciais ao processo metodológico desse autor bem como a algumas interpretações que ele apresenta. Essas reservas ou críticas só têm sentido em relação a um processo sociológico de conjunto que, apesar de tratar de questões bem próximas, é bem diferente do que foi realizado por Peterson. Seria assim possível imaginar que basta constatar o paralelismo das pesquisas sem estabelecer um diálogo entre elas. Mas cabe também pensar que os trabalhos de Peterson teriam maior alcance se fossem considerados uma contribuição específica à análise mais geral da variação intra-individual das práticas e preferências culturais sob o aspecto do grau de legitimidade dessas práticas e preferências.

As principais diferenças, tanto empíricas quanto metodológicas e teóricas, entre meu trabalho e o de Peterson, podem ser resumidas em cinco pontos de importância desigual.

1) Enquanto Peterson concentra a atenção no domínio musical e prospecta a diversidade dos gostos dentro desse domínio (variações intergêneros musicais), ampliei a área de observação a campos culturais diferentes - leitura, música, cinema, televisão, passeios culturais e lazeres - para melhor abranger a idéia de "estilo de vida cultural", o que me permite verificar tanto as variações intra-individuais de comportamentos de um domínio cultural para outro (variações interdomínios) quanto as variações intra-individuais de comportamentos dentro de 
um mesmo domínio cultural (variações intradomínios culturais). Já Peterson tende a generalizar sua proposta para todos os comportamentos culturais, embora seus dados se restrinjam quase sempre ao domínio musical. Como lembraram Van Rees, Vermunt e Verboord, a interpretação de Peterson e seus colaboradores "exige dados sobre um amplo espectro de preferências e práticas culturais (música, leitura, televisão, filmes, esporte etc.) e não relativos apenas a um único setor cultural" (Van Rees, Vermunt e Verboord, 1999:350).

2) Como já observei anteriormente, enquanto Peterson se refere ao problema das preferências musicais, ampliei a questão para práticas e preferências culturais, mostrando que, no fundo, os atores sociais não se definem apenas e, às vezes, nem principalmente, por suas preferências, mas pelas práticas efetivas. Em matéria cultural como em tantas outras, existem práticas de acompanhamento e uma infinidade de práticas não "escolhidas", mas que são o resultado de compromisso com o cônjuge ou os amigos, e práticas decorrentes de hábitos ou de automatismos, mas que não estão subjetivamente associadas a gostos, preferências ou paixões. Certos indivíduos passam às vezes mais tempo fazendo coisas ou consumindo produtos culturais sem acentuado "gosto pessoal" por essas coisas ou por esses produtos, do que externando preferências culturais que mostrem sua "identidade cultural pessoal".

Ora, a idéia de consumidor "onívoro" tende a concentrar nos próprios indivíduos (em suas propriedades intrínsecas) o que é apenas produto do encontro entre seus patrimônios de disposições, de apetências ou competências incorporadas, e determinados contextos institucionais ou relacionais. A metáfora zoológica leva Peterson a só considerar a variedade dos gostos, ao passo que parte importante da variedade das práticas e preferências é explicável tanto pela diversidade dos contextos e dos motivos nos / pelos quais os consumidores são levados a agir quanto pelo ecletismo pessoal ou pela multiplicidade das propensões culturais interiorizadas. Ao reduzir o conjunto de casos de variações intra-individuais das preferências musicais ao modelo do ecletismo cultural, Peterson parece ceder a um certo modismo estético e cultural.

A desconsideração, nas grandes enquetes estatísticas, das circunstâncias particulares ou das condições mais recorrentes nas quais os atores são levados a "consumir" este ou aquele produto cultural, dos motivos ou "motivações" que acompanham suas práticas, contribui para aplanar a realidade social e igualar práticas ou gostos que não são equiva- 
lentes. A metáfora zoológica, que fica nas mentes, é portanto potencialmente perigosa na medida em que pode levar a pensar - o que é desmentido claramente pelos dados das entrevistas - que os consumidores praticam tudo o que declaram praticar ou gostam de tudo o que declaram gostar com a mesma intensidade, nas mesmas condições e pelos mesmos "motivos" (ou com as mesmas "motivações"). O onívoro, como diz o dicionário, "nutre-se indiferentemente de alimentos de origem animal ou vegetal". Ora, os consumidores culturais nunca se apropriam indiferentemente dos produtos pertencentes aos diferentes registros culturais (dos mais divertidos aos mais sérios, dos mais comerciais aos mais puros, dos mais populares aos mais eruditos etc.).

3) Peterson e seus colegas não conseguem de fato mostrar as provas da existência de uma estética radicalmente "nova" (mais eclética ou mais heterogênea que "antes"). É impossível passar da constatação histórica (bem documentada pelo historiador Laurence W. Levine) segundo a qual teria havido períodos de separações mais fortes (e até de oposições) dos gêneros, das artes e dos públicos, à dedução sociológica segundo a qual os membros das classes dominantes teriam sido mais monocultos no início do século XX, e ter-se-iam tornado mais multicultos a partir dos anos 1970-1980. Como destaquei (Lahire, 2004:166-174), os dados de enquetes dos anos 1960 na França levam a pensar que o homo pluralis já existia nessa época, mas que as condições públicas (a natureza do debate público e das problematizações culturais) e científicas não eram favoráveis à sua divulgação. Nos períodos em que as distâncias entre registros legítimos e populares são menos pronunciadas, os comportamentos culturais "desviantes" da elite podem ser declarados publicamente com mais facilidade, em vez de ficarem confinados no espaço privado. O próprio Peterson cita dados mais antigos ${ }^{16}$ que tendem a pôr em dúvida a idéia de entrada em um "novo" mundo (chamado às vezes de pós-moderno). Parece-me haver aqui um erro de interpretação bem conhecido em ciências sociais, ou seja, a confusão de uma mudança de modelo da realidade (do ponto de vista de conhecimento sobre o mundo) com uma mudança histórica na própria realidade (na natureza das práticas culturais e das relações com a cultura).

4) Peterson constata entre as elites uma tendência ao consumo onívororaros são os que ficam nos registros culturais mais legítimos - e interpreta esse fato como forma de "ecletismo cultural" em relação à tendência ao consumo unívoro que seria muito mais pregnante nas classes populares. Ora, ao abrir o campo de investigação como fiz, percebe-se 
que todas as classes sociais então envolvidas, em um ou em outro grau, por essa variação intra-individual de um registro cultural ao outro. Se as análises que desenvolvi mostraram a importância de perfis culturais dissonantes ("onívoros", segundo a terminologia de Peterson) entre os dirigentes e profissionais intelectuais superiores $(74,3 \%)$, mostraram também e sobretudo a predominância desses perfis entre a juventude escolarizada (83\%) e os dirigentes médios (79\%). Logo, a simples hipótese referente à emergência de novas elites ou de novos comportamentos culturais entre as elites não se sustenta. Do mesmo modo, é difícil qualificar de "unívoros" os membros das classes populares que têm muito mais chance estatística de ter um perfil cultural dissonante $(60,9 \%$ dos empregados; $58,5 \%$ dos operários qualificados; e $47 \%$ dos operários não-qualificados) do que um perfil consonante pouco legítimo (respectivamente, $18,3 \% ; 24,6 \%$; e $26,7 \%$ ).

Todos esses fatos impõem, portanto, uma interpretação bem mais ampla da estrutura e do funcionamento geral de nossas sociedades, como tenho tentado demonstrar neste artigo: com uma estrutura muito fragmentada, mas sempre hierarquizada, da oferta cultural, uma multidão de pequenas mobilidades sociais, profissionais e escolares tanto intergenerativas como intragenerativas, uma pluralização dos quadros de socialização (familiares, escolares, profissionais, culturais etc.) nos quais os atores dessas sociedades são levados a se construir-formar-fabricar e uma transformação significativa do modo de seleção escolar de todos os alunos (e não apenas das elites).

As hipóteses formuladas por Peterson e seus colaboradores a respeito das causas do caráter onívoro dos consumos culturais parecem-me amplas demais e às vezes até um pouco idealistas quando consideram as raízes morais das atitudes culturais. Assim, quando Peterson e Kern lembram que, desde o período nazista, todo comportamento que possa ser julgado racista é mal recebido e que a passagem "de esnobe exclusionista para onívoro inclusionista pode assim ser vista como parte da tendência histórica a uma maior tolerância com respeito a valores diferentes" (1996:905), esses autores cedem a uma espécie de angelismo abstrato, sociologicamente pouco realista. Além do fato de não estar provado que os consumidores com mais alto nível de educação tenham efetivamente vivido em um gueto cultural legítimo durante os períodos em que a separação nítida entre "cultura erudita" e "cultura popular" era explicitamente reivindicada e institucionalmente organizada, o angelismo sociológico da explicação por vontade de "mostrar respei- 
to pelas expressões culturais de outrem" corresponde mal à realidade das lutas de classificação que toda enquete sobre práticas culturais consegue pôr em evidência.

Declarar que se gosta de um número maior de gêneros musicais do que as outras pessoas será por acaso sinal de mais tolerância ou apenas o reflexo de um conhecimento musical mais extenso que não exclui uma hierarquização simbólica muito rígida? Inversamente, será que não gostar de certos gêneros musicais significa necessariamente "intolerância"? Não apreciar uma coisa não é um sentimento incompatível com aquele que consiste em pensar que outros têm todo o direito de gostar dela. Os consumidores das classes populares, que são mais numerosos que os das classes superiores ao designar um maior número de gêneros musicais de que não gostam, são assim não apenas qualificados de "unívoros" mas também suspeitos de intolerância (ou, para usar um eufemismo, de "falta de tolerância"). E certos pesquisadores sentem-se com direito de perguntar de forma mais geral, com a boa consciência do etnocentrista que se ignora: "Serão os 'unívoros' menos tolerantes em outros pontos?" (Bryson, 1997:150). O intérprete vai rápido demais e traça espontaneamente um retrato mais favorável das novas elites mais tolerantes, mais ecléticas, menos sectárias (seria possível dizer "culturalmente cosmopolitas"), do que das classes populares mais restritas, menos tolerantes e menos abertas.

5) O modo de administração da prova utilizado por Peterson e seus colaboradores não está plenamente adaptado à hipótese que pretendem validar, pois não é mostrando a existência de certa diversidade de gostos culturais entre as elites que se pode provar o caráter "onívoro" dos membros da elite. De fato, Peterson permanece fechado em um raciocínio e em uma metodologia na escala do grupo no seu conjunto, ao passo que sua hipótese e interpretação supõem que ele estabeleça sua constatação de variedade cultural em escala individual, sobre os membros do grupo, desenvolvendo o mesmo procedimento utilizado por mim. É também a crítica que lhe fazem Van Rees, Vermunt e Verboord quando afirmam que, para que as hipóteses de Peterson sejam válidas, os comportamentos culturais "devem ser medidos em nível individual e não em nível agregado de status ocupacional" (1999:350) ${ }^{17}$. É possível opor-lhe absolutamente o fato de ele não mostrar comportamentos individuais "onívoros" e que a variedade cultural estabelecida no nível do grupo pode simplesmente significar a existência de uma infinidade 
de pequenos subgrupos ou frações de grupos "unívoros", mais especialmente interessados por este ou aquele gênero musical.

Se Peterson e seus colaboradores não conseguem tirar todas as conseqüências de seus resultados é porque sua cultura teórica não os torna sensíveis à questão da escala de análise a partir da qual emitem suas constatações e não lhes permite inserir em sua análise a questão da variação intra-individual dos comportamentos culturais e a outra, correlativa, de seus determinantes sociais (ou seja, da pluralidade das influências socializadoras e dos contextos de práticas/consumos que se encontra na origem dessa variação).

De modo diverso de Richard A. Peterson, cuja teoria sociológica geral permanece bem discreta e implícita, meu estudo funda-se em um programa científico que é o da sociologia do social em escala individual. Essa sociologia, que se interessa pelo social incorporado, individualizado, assim como pelas variações intra-individuais dos comportamentos, é levada a questionar a noção de habitus (invocada por Pierre Bourdieu para explicar culturas ou hábitos de grupos ou de classes) como sistema de disposições transferível ou como fórmula geradora (única) das práticas (Lahire, 2003).

Pressupondo amplamente um mecanismo geral de transferibilidade cultural em ação, Pierre Bourdieu de fato nunca testou essa hipótese em seus trabalhos empíricos. Assim, o sentido de legitimidade cultural adquirido em um domínio seria implicitamente transferível para os outros domínios (Bourdieu e Darbel, 1969:99-100). Dois motivos principais são invocados para apoiar a idéia de transferência. O primeiro é uma espécie de atribuição estatutária e de sentido da dignidade e do dever culturais que faz com que, considerando a posição social, o nível de escolaridade etc., do indivíduo altamente escolarizado, ele tenha de fazer de tudo para "manter sua posição" seja qual for o domínio considerado. O segundo é o de uma competência técnica (uma série de hábitos intelectuais) que, inicialmente construída na escola a partir do estudo de obras literárias ("uma aptidão, também generalizada e transferível à classificação por autores, gêneros, escolas ou épocas"), permite saber, por analogia, que direção tomar para apropriar-se legitimamente das obras extraliterárias (pintura, música, teatro, cinema etc.).

Mas um dos grandes pressupostos do modelo de transferência generalizado é também a homogeneidade (sob o ângulo da legitimidade cultural) das múltiplas situações culturais vividas pelos atores. Em outras 
palavras, sem dizer claramente, o sociólogo formula a hipótese de que o que é legítimo e desejável aqui continua a sê-lo também ali. Movido por um "é mais forte que eu" cultural, o ator não teria nenhuma noção das situações e sempre empregaria as mesmas disposições culturais sejam quais forem as pessoas com quem se encontra (independentemente de suas propriedades sociais e culturais) e seja qual for a natureza - formal ou informal, tensa ou distendida - da situação.

Além disso, aposto cientificamente que é possível tornar mais complexo o quadro da realidade social se for dada mais atenção à complexidade dos indivíduos socializados. Essa complexidade deve-se a dois grandes motivos: a) os indivíduos são, em nossas sociedades, sujeitos a experiências socializadoras heterogêneas e às vezes até contraditórias (o que vale em matéria de cultura como em outras áreas) e são, por isso, portadores de uma pluralidade de disposições, apetências e competências; b) esses mesmos indivíduos não são levados a agir sempre nas mesmas condições, nos mesmos contextos de ação e seus patrimônios individuais de disposições, apetências e competências estão portanto sujeitos a solicitações variáveis (Lahire, 1998; 2002; 2003).

Essa reflexão de fundo referente aos objetos da sociologia leva-me a indagar outra vez os (bons e maus) motivos que fizeram com que, de Émile Durkheim a Pierre Bourdieu, os sociólogos tenham tido a tendência de deixar de lado as realidades sociais em escala individual ${ }^{18}$. E é esse tipo de indagação - que Richard A. Peterson não faz - que obriga à adoção de uma metodologia adaptada, partindo sobretudo da construção de perfis culturais individuais (a gama de suas práticas e preferências mais ou menos legítimas em áreas culturais variadas) antes de colocar os indivíduos em categorias (idade, sexo, socioprofissional ou cultural). É sobre esses desafios mais gerais para a sociologia que pretendo agora concluir.

\section{SOCIALIZAÇÕES MÚLTIPLAS E INDIVÍDUO COMO MISTURA DE GÊNEROS}

O sociolingüista William Labov sempre destacou em suas enquetes que é raro encontrar "locutores de estilo único". O estilo lingüístico varia em um mesmo locutor de uma para outra situação, e sobretudo em função de seu grau de oficialidade. Quanto mais tensa e formal é a situação, tanto mais o locutor tenta conformar-se ao estilo (registro lexical e sintático, pronúncia) mais legítimo. Os locutores se diferenciam, é claro, de acordo com a gama mais ou menos ampla de estilos lingüísti- 
cos de que dispõem, mas todos conhecem variações mais ou menos fortes de suas produções de linguagem (Labov, 1976) ${ }^{19}$.

Mutatis mutandis, cabe afirmar que ébem mais raro encontrar consumidores culturais uniestilo que consumidores culturais pluriestilos. E, como para as produções de linguagem, as variações observáveis explicam-se essencialmente pela pluralidade dos contextos culturais nos quais os atores foram socializados no decurso de seu passado e que são levados a freqüentar durante suas múltiplas interações presentes: heterogeneidade das condições de socialização culturais passadas e pluralidade dos contextos de práticas ou de consumos culturais presentes.

É o interesse sociológico das variações intra-individuais dos comportamentos que tento destacar no âmbito de uma sociologia da pluralidade disposicional (a socialização passada é mais ou menos heterogênea e proporciona disposições heterogêneas e às vezes contraditórias) e contextuais (os contextos de atualização das disposições são variados). Assim, o ator individual não aciona invariavelmente, transcontextualmente o mesmo sistema de disposições (ou habitus), mas podem observar-se mecanismos mais sutis de entrada em descanso/entrada em ação ou de inibição/ativação de disposições; mecanismos que supõem, evidentemente, que cada indivíduo é portador de uma pluralidade de disposições e atravessa uma pluralidade de contextos sociais. O que determina a ativação de tal disposição em tal contexto é então o produto da interação entre relações de força interna e externa: relações de força entre disposições mais ou menos fortemente constituídas durante a socialização passada (interna) e relações de força entre elementos (características objetivas da situação, que podem ser associadas a pessoas diferentes) do contexto que pesam mais ou menos sobre o ator (externo).

A medida da amplidão dos fenômenos de "perfis culturais dissonantes" leva não apenas a conceder um lugar entre as ciências sociais à interrogação sobre as variações intra-individuais dos comportamentos o que ainda não é muito conhecido (Lahire, 1998; 2002 e 2004:695-736) mas também a elaborar uma teoria do ator indissociavelmente disposicionalista e contextualista que se diferencia tanto das teorias sociológicas que esquecem os contextos (suas especificidades e suas variações) explicando tudo pela cultura, pela mentalidade, pelo código de comportamento ou pelo sistema de valores ou de disposições de que seriam portadores os indivíduos, quanto das teorias que, ao contrário, colocam toda a explicação do lado dos contextos, de suas estruturas ou de 
suas possibilidades (Gibson, 1979). Só uma sociologia da pluralidade disposicional e contextual pode explicar da forma mais completa possível esses fenômenos (muito regulares e também objetiváveis estatisticamente quanto os ligados aos grupos) de variações intra-individuais dos comportamentos culturais.

Nas sociedades social e culturalmente diferenciadas, os mesmos indivíduos freqüentam quase sempre sucessiva ou alternativamente vários registros culturais (dos mais legítimos aos menos legítimos, passando pelos que estão em via de legitimação). As realidades microscópicas (as variações intra-individuais e interindividuais), quase sempre ignoradas por motivos teóricos pelas ciências sociais, remetem às propriedades mais fundamentais da realidade macroscópica. O espaço de investigação que se abre ao leitor é o de uma sociologia em escala individual que analisa a realidade social levando em conta sua forma individualizada; uma sociologia que leva em consideração que traços de experiências socializadoras diferentes, e às vezes contraditórias, podem (co)habitar (no) mesmo corpo, que disposições mentais e comportamentais mais ou menos duravelmente incorporadas podem manifestar-se ou ser mantidas latentes nos diferentes momentos da vida social (segundo os domínios da prática) ou de um percurso biográfico.

A sociologia tem assim os meios teóricos e metodológicos de dar corpo à idéia segundo a qual cada indivíduo pode ser definido - tendo em vista a pluralidade de influências socializadoras que pode ter vivido e a diversidade dos contextos nos quais é levado a agir - como uma "mistura de estilos" ou uma "mistura de gêneros".

(Recebido para publicação em maio de 2007) (Versão definitiva em julho de 2007) 


\section{NOTAS}

1. O procedimento metodológico complexo utilizado a partir da enquete "Práticas culturais dos franceses - 1997" (DEP/Ministério da Cultura; $\mathrm{n}=3.000$ ) e que permite enunciar sinteticamente tais resultados é longamente exposto em Lahire (2004:117-207). Nele, o leitor encontra a explicação completa e os principais resultados dessa pesquisa. Os perfis culturais individuais foram construídos a partir de indicadores dos gêneros musicais mais ouvidos, os gêneros de livros mais lidos, os gêneros de filmes preferidos, os programas de televisão escolhidos, os gêneros de passeios ou de visitas culturais e os lazeres-divertimentos praticados. Esse procedimento estatístico foi completado por 111 entrevistas realizadas com pessoas de características sociais diversificadas (segundo a idade, o sexo, o nível de escolaridade, o tipo de formação escolar, a origem social e a posição socioprofissional).

2. E não se compreenderiam as evoluções individuais em matéria de práticas e de gostos culturais se não fossem reconstruídas as dinâmicas que fazem, de um simples hábito, paixão ou, ao contrário, algo que logo se abandona; que o que era obrigatório possa, ao final de um longo processo de interiorização ou por outras circunstâncias, transformar-se em gosto pessoal; que tudo o que era praticado para agradar aos outros se transforme em prática para o prazer pessoal, ou que o que era gosto ou paixão passe a ser simples hábito etc.

3. Neste texto não abordo tal ponto porque exige a explanação de uma longa série de argumentos e de provas empíricas. Mas ele está amplamente desenvolvido em Lahire (2004, cap. 14:497-555).

4. Para as análises minuciosas de cada um desses pontos, baseadas em uma longa série de elementos de provas empíricas, remeto à leitura de Lahire (2004:411-668).

5. Nossas análises coincidem nesse ponto com as de Erickson (1996).

6. Sobre a distinção entre "cultura quente" e "cultura fria", cf. a obra da helenista Florence Dupont (1994).

7. O filósofo Ludwig Wittgenstein dizia a respeito dos filmes norte-americanos a que gostava de assistir depois de um esforço intelectual intenso que eles tinham "o efeito de um bom banho de chuveiro" (Malcolm, 1988:336-337).

8. Cf. sobre esse ponto a análise do karaokê (Lahire, 2004:616-624) que, embora sendo o oposto da cultura da fria contenção, do domínio dos sentimentos ou das emoções característica dos apreciadores esclarecidos de museus ou dos espectadores de concertos de música clássica ou de ópera, pode fazer parte do programa de pessoas de forte capital cultural.

9. Convém lembrar que a porcentagem de lares franceses proprietários de um aparelho de tevê era, em 1960, de 13\% e, desde 1989, chegou a 96\%. Quanto ao rádio, passou de $5 \%$ em 1930 a $96 \%$ em 1973.

10. Isso não surpreende os leitores do sociolingüista norte-americano William Labov, cujas pesquisas mostram que o esforço dos locutores para falar em um registro padrão é tanto maior quanto a situação for pública e oficial (Labov, 1976).

11. Mede-se, por exemplo, o efeito da passagem dos filmes das salas de cinema para a televisão (com difusões múltiplas e possibilidade de gravação em vídeos ou DVD) sobre as características de seus públicos (Guy, 2000). Quanto mais antigos são os filmes, maior é a chance de serem vistos, e até apreciados, por um público diferente do que 
se havia deslocado para vê-los nas salas de cinema. Por um lado, os filmes de autor "reservados" inicialmente ao público mais diplomado e cinéfilo encontram assim públicos mais amplos que não se teriam deslocado nem pagado para vê-los com medo de se aborrecer ou de não entender nada, mas que têm a curiosidade de vê-los na tevê. Por outro lado, os filmes para um público maior e os menos legítimos (filmes de ação ou de aventuras, filmes policiais ou cômicos) podem ser vistos por públicos de exigências culturais habitualmente mais altas, que não teriam ido vê-los nos cinemas - nobreza cultural exige - mas que gostam de vê-los gratuitamente em casa, sem sentir vergonha cultural e sem estar junto de públicos de características sociais e culturais muito diferentes das suas.

12. Por exemplo, Marc Fumaroli, professor no Collège de France (Cátedra de Retórica e Sociedade na Europa - séculos XVI e XVII), declarou no final do século XX sua repulsa à confusão entre "o Fórum e o Circo, Quaresma e Carnaval" (1992:300-301); também Alain Finkielkraut, professor de filosofia na École Polytechnique e ensaísta, critica a "mestiçagem" de seus contemporâneos em La Défaite de la Pensée (1987).

13. Analisei a composição das atrações (de 2001 a 2002) de dois programas de grande audiência da televisão francesa - Tout le Monde en Parle [Todo o mundo fala disso] e On ne Peut pas Plaire à Tout le Monde [Não se pode agradar a todo o mundo] - em La Culture des Individus (Lahire, 2004:637-668).

14. Tais programas tratam da atualidade cultural, política e midiática. A respeito de Nulle Part Ailleurs, programa que fez parte do sucesso da cadeia francesa chamada Canal +, existe um trabalho de Le Guern e Teillet (2003).

15. Tema que se encontra tanto em um filósofo estudioso do declínio como Alain Finkielkraut (1987) como nos textos mais politicamente engajados do sociólogo Pierre Bourdieu (2001).

16. “De fato, nos anos 1960, Wilensky (1964:194) 'não conseguia achar um só que fosse, entre 1.354 moradores da área de Detroit, que, de alguma maneira, não houvesse tido contato com material de categoria média ou ruim' [...]" (Peterson e Kern, 1996:901).

17. Cf. também Van Eijck (2000).

18. Cf. "Post-Scriptum: Individu et Sociologie" (Lahire, 2004:695-736).

19. Dediquei em L'Homme Pluriel um parágrafo intitulado Code Switching et Code Mixing au Sein d'un Même Contexte que destaca a importância de uma parte da sociolingüística para a sociologia das variações contextuais dos comportamentos individuais (Lahire, 1998:74-76). 


\section{REFERÊNCIAS BIBLIOGRÁFICAS}

BEISEL, N. (1990), “Class, Culture, and Campaigns Against Vice in Three American Cities, 1872-1892". American Sociological Review, vol. 55, no 1, pp. 44-62.

BOURDIEU, P. (1979), La Distinction. Critique Sociale du Jugement de Goût. Paris, Minuit. . (2001), Contre-Feux 2. Paris, Seuil (Raisons d'Agir).

BOURDIEU, P. e DARBEL, A. (1969), L'Amour de l'Art. Les Musées d'Art Européens et leur Public. Paris, Minuit.

BOURDIEU, P. et alii. (1965), Un Art Moyen, Essai sur les Usages de la Photographie. Paris, Minuit.

BRYSON, B. (1997), "What about the Univores? Music Dislikes and Group-Based Identity Construction among Americans with Low Levels of Education". Poetics, no 25, pp. 141-156.

CASSAVETTI, H. (2002), “Un Drôle de Paroissien”. Télérama, 9-15 mars.

CHARTIER R. (1989), “Le Monde comme Représentation”. Annales ESC, ano 44, no 6, pp. $1.505-1.520$.

DUMONTIER, F., SINGLY, F. de e THÉLOT, C. (1990), “La Lecture Moins Attractive Qu'il y a Vingt Ans". Économie et Statistique, no 233, pp. 63-80.

DUPONT, F. (1994), L'Invention de la Littérature. De l'Ivresse Grecque au Livre Latin. Paris, La Découverte.

ELIAS, N. e DUNNING, E. (1994), Sport et Civilisation. Paris, Fayard.

ERICKSON, B. H. (1996), "Culture, Class and Connections". American Journal of Sociology, vol. 102, no 1, pp. 217-251.

FISH, S. (1980), Is There a Text in This Class? The Authority of Interpretive Communities. Cambridge/London, Harvard University Press.

FINKIELKRAUT, A. (1987), La Défaite de la Pensée. Paris, Gallimard.

FUMAROLI, M. (1992), L'État Culturel. Essai sur une Religion Moderne. Paris, Le Livre de Poche.

GIBSON, J. J. (1979), The Ecological Approach to Visual Perception. Boston, Houghton Mifflin.

GOBLOT, E. (1925), La Barrière et le Niveau. Étude Sociologique sur la Bourgeoisie Française Moderne. Paris, Félix Alcan.

GRIGNON, C. e PASSERON, J.-C. (1989), Le Savant et le Populaire. Misérabilisme et Populisme en Sociologie et en Littérature. Paris, Gallimard/Seuil (Hautes Études).

GUY, J.-M. (2000), La Culture Cinématographique des Français. Paris, DEP/Ministère de la Culture (La Documentation Française).

LABOV, W. (1976), Sociolinguistique. Paris, Minuit.

LAHIRE, B. (1998), L'Homme Pluriel. Les Ressorts de l'Action. Paris, Nathan (Essais \& Recherches). 
. (1999), L'Invention de l' Illettrisme". Rhétorique Publique, Éthique et Stigmates. Paris, Éditions la Découverte (Laboratoire des Sciences Sociales).

. (2002), Portraits Sociologiques. Dispositions et Variations Individuelles. Paris, Nathan (Essais \& Recherches).

. (2003), "From the Habitus to an Individual Heritage of Dispositions. Towards a Sociology at the Level of the Individual". Poetics, Journal of Empirical Research on Culture, the Media and the Arts, vol. 31, pp. 329-355.

. (2004), La Culture des Individus. Dissonances Culturelles et Distinction de Soi. Paris, Éditions la Découverte (Laboratoire des Sciences Sociales).

. (2005), "Distinctions Culturelles et Lutte de Soi Contre Soi : “Détester la Part Populaire de Soi". Hermès, Revue Cognition Communication Politique, no 42, pp. 137-143.

LE GUERN, P. e TEILlET, P. (2003), "Canal Plus" de Légitimité? Les Processus Médiatico-Publicitaires de Consécration Culturelle à l'Émission Nulle Part Ailleurs". Réseaux, n0 117, pp. 110-132.

LEVINE, L. W. (1988), Highbrow/Lowbrow: The Emergence of Cultural Hierarchy in America. Cambridge, Harvard University Press.

LYNES, R. (1954), The Tastemakers. New York, Harper.

MALCOLM, N. (1988), "Ludwig Wittgenstein", in L. Wittgenstein, Le Cahier Bleu et le Cahier Brun. Paris, Gallimard, pp. 331-424.

MURPHY, R. (1988), Social Closure: The Theory of Monopolization and Exclusion. Oxford, Clarendon.

PASSERON, J.-C. (1991), Le Raisonnement Sociologique. L'Espace Non-Poppérien du Raisonnement Naturel. Paris, Nathan (Essais \& Recherches).

PETERSON, R. A. e KERN, R. M. (1996), “Changing Highbrow Taste: From Snob to Omnivore". American Sociological Review, vol. 61, no 5, pp. 900-907.

PETERSON, R. A. e SIMKUS, A. (1992), How Musical Tastes Mark Occupational Status Groups", in M. Lamont e M. Fournier (eds.), Cultivating Differences: Symbolic Boundaries and the Making of Inequality. Chicago/London, The University of Chicago Press, pp. 152-186.

VAN EIJCK, K. (2000), “Richard A. Peterson and the Culture of Consumption". Poetics, no 28 , pp. 207-224.

VAN REES, K., VERMUNT, J. e VERBOORD, M. (1999), “Cultural Classifications under Discussion. Latent Class Analysis of Highbrow and Lowbrow Reading". Poetics, no 26, pp. 349-365.

VEBLEN, T. (1978) [1899], Théorie de la Classe de Loisir. Paris, Gallimard.

VERRET, M. (1988), La Culture Ouvrière. Saint-Sébastien, A.C.L.

WILENSKY, H. L. (1964), "Mass Media and Mass Culture: Interdependence or Independence?". American Sociological Review, vol. 29, no 2, pp. 173-197. 


\section{ABSTRACT \\ Individual and Gender Mix: Cultural Dissonances and Selfness}

The examination of cultural practices and preferences based on intra-individual behavior variation fosters a portrait of the social world that does not rule out individual singularities and that avoids cultural caricatures of social groups, thereby revealing that the border between "cultural legitimacy" and "cultural illegitimacy" not only separates different social classes, but also shares the different cultural practices and preferences by the same individuals in all classes. Without questioning the existence of social inequalities vis-à-vis the more legitimate cultural forms, this approach allows highlighting the statistical frequency of individual cultural profiles formed by heterogeneous and dissonant elements. Consideration of the socio-historical conditions in the production of heterogeneous cultural profiles unveils the consequences of these frequent cultural dissonances from the perspective of interpreting the social functions of culture, thus emphasizing the interest in studying individual variations in behaviors within a sociology of dispositional and contextual plurality.

Key words: genders; cultural practices; behavior

\section{RÉSUMÉ}

Individu et Mélanges des Genres: Dissonances Culturelles et Distinction de Soi

En envisageant les pratiques et les préférences culturelles sous l'angle de la variation intra-individuelle des comportements, on aboutit à un tableau du monde social qui ne néglige pas les singularités individuelles et évite la caricature culturelle des groupes sociaux. Le fait central qui apparaît alors est que la frontière entre la "légitimité culturelle" et 1'“illégitimité culturelle" ne sépare pas seulement les différentes classes sociales, mais partage les différentes pratiques et préférences culturelles des mêmes individus, dans toutes les classes. Sans remettre en cause l'existence d'inégalités sociales devant les formes culturelles les plus légitimes, un tel point de vue de connaissance permet de mettre en évidence la forte fréquence statistique des profils culturels individuels composés d'éléments hétérogènes ou dissonants. Après être revenu sur les conditions socio-historiques de production de profils culturels hétérogènes, on peut tirer les conséquences de ces fréquentes dissonances culturelles du point de vue de l'interprétation des fonctions sociales de la culture et souligner l'intérêt de l'étude des variations 
Indivíduo e Mistura de Gêneros: Dissonâncias Culturais e Distinção de Si

intra-individuelles des comportements dans le cadre d'une sociologie de la pluralité dispositionnelle et contextuelle.

Mots-clé: genres; pratiques culturelles; comportements 